\title{
Effects of the Schedule and Duration of the Posts for Emergency Medicine Residents on Their Social Life and Practice
}

\author{
(1) İsmail Ağı ${ }^{1}$, (1) Bedriye Müge Sönmez ${ }^{2}$, (1) Murat Doğan Ișcanlı², (1) Sultan Erdil Ülgen ${ }^{3}$ \\ ${ }^{1}$ Clinic of Emergency Medicine, Yozgat City Hospital, Yozgat, Turkey \\ ${ }^{2}$ Clinic of Emergency Medicine, University of Health Sciences Turkey, Ankara Numune Training and Research Hospital, Ankara, Turkey \\ ${ }^{3}$ Clinic of Emergency Medicine, Sorgun State Hospital, Yozgat, Turkey
}

\begin{abstract}
Aim: To determine the working order of the emergency medicine (EM) residents, their individual preferences, and the effects of their working order on their practice and social lives.

Materials and Methods: A total of $182 \mathrm{EM}$ residents were included in this study. A two-stage questionnaire study was designed, including a questionnaire on demographics and on the residents' thoughts regarding their practice and social lives. This study included EM residents who were actively on duty with shifts and volunteered to participate. All data were analyzed using SPSS software.

Results: The most common shift type practiced among the residents was the 8/16 duty system. Most of the residents were working on 24-hour shifts (42.1\%). Of the residents, 54.9\% stated that their concentration levels were negatively affected after 8-10 hours of duty. Although 102 (56.1\%) of the physicians were glad to be EM residents and 19 (10.4\%) believed that they had enough time for themselves, 22 (12.1\%) stated that they were only able to sufficiently study when they were off duty. Sleeping issues were statistically lower in EM residents working on 24hour shifts. A higher percentage of residents on duty in a periodical order stated that they could get sufficient rest. Meanwhile, an unstable relationship with patients and negative views on medical practice were observed more frequently among residents who were on duty with irregular shifts.
\end{abstract}

Conclusion: Shift systems and the regularity of shifts affect not only the residents' social lives but also their approach to patients.

Keywords: Duty, emergency medicine, practice-social life

\section{Introduction}

Physicians practicing emergency medicine (EM) are under constant duress due to the workload, continuous confrontation with patients in critical condition, andworking in shifts. Only working in shifts has been sufficient reason for stress (1). Increase in the duration of shifts based on lack of staff also damages the already fragile social, familial and peer relations of the residents (2). This condition has been known as "burn-out syndrome"(3).

Increasing stress, along with the discontent at work and the loss of eagerness lead to a depres-sive emotional state/mood especially at the end of the 40 s and decrease the quality of patient care $(3,4)$. Beyond, shift patterns have a strong effect on balancing stres of emergency physicians (5). The most convenient shift pattern defined worldwide has been the arrangement of day, evening and night shifts. Usually a 24-hour episode is necessary in every night duty for the in-dividual to restore his/her strength and social life (4).

In the present study we aimed to identify the practice patterns of EM residents, and how these patterns effect the residents' work lives and social lives.

\section{Materials and Methods}

\section{Study Design}

This prospective study was performed with the Institutional Review Board protocol approval date: 01/06/2016 and number: E-16-938 in the emergency department of Ankara Numune 
Training and Research hospital. This study has been conducted in compliance with the latestversion of "Helsinki Declaration" and the "Good Clinical Practice Directive".

\section{Data Collection}

Survey has been performed through a questionnaire study applied to residents practicing in emergency services of random hospitals. One hundred and eighty-two EM residents have participated the questionnaire study. Questionnaire study was designed as a two-stage survey. Survey was applied the day after the post. Demografic data evaluated in the first group comprises of the duration of residency, age, gender, diseases, height, weight, use of alcohol and/or cigarettes, category of hospital (training and research hospital/ university hospital), number of posts, type of shifts, and the pattern of shifts. Second group of questions on the other hand, concentrates on investigating the thoughts of participants on their Professional lives and on their social lives.

Shift patterns have been categorized as: 8/16 shift system comprising of 8 hours of day and 16 hours of nightduty; 12/12 shift system comprising of 12-hour periods of duty; and 24 hours shift system for 24 hours non-stop duty. Study included residents in ER units who were actively engaged, who were on duty with shifts, and who were volunteer to participate in the study. Any resident who were not practicing actively or not on duty shifts for any reason (e.g. maternity leave, sickleave), who did not volunteer to participate, and who did not complete the questionnaire form were excluded from present study.

\section{Data Analysis}

All data were analyzed with SPSS (Statistical Package for the Social Sciences) software for Windows (v21.0; IBM, Armonk, NY, USA). Individual and aggregate data were summarized using descriptive statistics including mean, standart deviations, medians (min-max), frequency distributions and percentages. Initial evaluations and comparison of the data for normal distribu-tion was made via Kolmogorov-Smirnov and ShapiroWilk tests. Comparison of the dependent variables with normal distribution was made with Student t-test and ANOVA. For the continuous variables that were not normally distributed, the Kruskall-Wallis and Mann-Whitney $U$ test were conducted to compare between groups. Presence of correlation was analyzed with Spear-man's Rho and Pearson tests. P values of $<0.05$ were considered statistically significant.

\section{Results}

Socio-demographic features and the practice patterns of the resident physicians included in the study has been shown in Table 1 and Table 2. As well as the most common type of shifts practiced were 8/16 duty systems among the residents who
Table 1. Socio-demographic features and the work order of the participants

\begin{tabular}{|c|c|}
\hline & Mean \pm SD (Median)/n (\%) \\
\hline Age & $30.1 \pm 3.9(30)$ \\
\hline \multicolumn{2}{|l|}{ Gender } \\
\hline Male & 109 (59.9) \\
\hline Female & $73(40.1)$ \\
\hline \multicolumn{2}{|l|}{ Duration } \\
\hline$<13$ months & $32(17.6)$ \\
\hline $13-24$ months & $42(23.1)$ \\
\hline $25-36$ months & $40(22.0)$ \\
\hline$\geq 36$ months & $68(37.4)$ \\
\hline Chronic diseases & $25(13.7)$ \\
\hline Cigarettes & $85(46.7)$ \\
\hline Alcohol & $96(52.7)$ \\
\hline \multicolumn{2}{|l|}{ Type of hospital } \\
\hline Training and research hospital & $77(42.3)$ \\
\hline Medical hospital & $105(57.7)$ \\
\hline Monthly average hours of work & $213.4 \pm 26.8(216)$ \\
\hline $\begin{array}{l}\text { Monthly average number of } \\
\text { nightposts }\end{array}$ & $8.9 \pm 1.1(9)$ \\
\hline
\end{tabular}

Table 2. Practiced shifts and preferences

\begin{tabular}{|c|c|c|c|}
\hline & Total & Female & Male \\
\hline & $(n=182)$ & $(n=73)$ & $(n=109)$ \\
\hline \multicolumn{4}{|c|}{ Type of shift practiced } \\
\hline $8 / 16(n=104)$ & $104(57.1 \%)$ & $42(57.5 \%)$ & $62(56.9 \%)$ \\
\hline $12 / 12(n=13)$ & $13(7.1 \%)$ & $8(11 \%)$ & $5(4.6 \%)$ \\
\hline $24(n=47)$ & $47(25.8 \%)$ & $14(19.2 \%)$ & $33(30.3 \%)$ \\
\hline $8 / 8 / 8(n=1)$ & $1(0.5 \%)$ & $1(1.4 \%)$ & $0(0 \%)$ \\
\hline Other $(n=17)$ & $17(9.3 \%)$ & $8(11 \%)$ & $9(8.3 \%)$ \\
\hline \multicolumn{4}{|c|}{ Preferred shift type } \\
\hline $8 / 16(n=104)$ & $57(31.3 \%)$ & $31(42.5 \%)$ & $26(23.9 \%)$ \\
\hline $12 / 12(n=13)$ & $20(11 \%)$ & $8(11 \%)$ & $12(11 \%)$ \\
\hline $24(n=47)$ & $55(30.2 \%)$ & $14(19.2 \%)$ & $41(37.6 \%)$ \\
\hline $8 / 8 / 8(n=1)$ & $46(25.3 \%)$ & $19(26 \%)$ & $27(24.8 \%)$ \\
\hline Other $(n=17)$ & $4(2.2 \%)$ & $1(1.4 \%)$ & $3(2.8 \%)$ \\
\hline \multicolumn{4}{|c|}{ Content with the type of shift } \\
\hline $8 / 16(n=104)$ & $39(37.5 \%)$ & $21(50.0 \%)$ & $18(29.0 \%)$ \\
\hline $12 / 12(n=13)$ & $5(38.5 \%)$ & $1(12.5 \%)$ & $2(40.0 \%)$ \\
\hline $24(n=47)$ & $20(42.1 \%)$ & $3(21.4 \%)$ & $16(48.5 \%)$ \\
\hline $8 / 8 / 8(n=1)$ & - & - & - \\
\hline Other $(n=17)$ & $2(11.8 \%)$ & $1(12.5 \%)$ & $1(11.1 \%)$ \\
\hline
\end{tabular}


have participated in the study, 8/16 shift has been also the most commonly preferred duty system by them (31.3\%). As to the residents' content with their shift pattern, the highest level of satisfaction belonged to the residents work-ing with 24-hour shifts (42.1); as this percentage was typical for the male residents in 8/16 shift pattern, also female residents who practiced in 24hour shift pattern were content with their pattern.

Of the residents participating in the study $54.9 \%$ were indicated that their concentration levels was affected negatively after 8-10 hours of practice. Also after 8-10 hours of work, 39\% of the participants think that they may decide incorrectly in the treatment process; 36.3 of them consid-er that the frequency of occupational accidents increases; $47,8 \%$ of them state that they start to feel tired; $28 \%$ of them say that they feel exhausted; $41.2 \%$ declare that their relations with the patients and patient relatives have been effected negatively; and $34.1 \%$ of them point out that they begin to view their profession negatively (Table 3).

It has been established by the study that the 102 (56.1\%) of the participants have been content to be emergency medicine residents, while 38 (20.9\%) of them were not. As 28 (15.3) of them have the idea that they spend enough time with their families, 100 (55\%) of them think that they do not. As 20 (11\%) of residents think they have enough time for their friends and 19 (10.4\%) of residents have the idea that they have enough time for themselves. While 21 (11.5\%) of the residents consider that they have enough spare time for their hobbies, 132 (72.6) of them think that they do not. As 22 (12.1\%) of them are convinced that they can study enough in their off-duty period, 136 (74.7\%) of them think that they can not study sufficiently in their off-duty time. As 38 (20.8\%) of the residents stated that they have no problems like having difficulty in falling asleep, waking up frequently, or not having enough sleep; whereas 114 (62.7\%) of them reported as having one of the problems like having difficulty in falling asleep, waking up frequently, or not having enough sleep. As 126 (69.2\%) of the residents are of the opinion that being on duty for a long period of time has a negative effect on health, 39 (21.4\%) of them think that being on duty for a long period of time has no negative effect on health. While 129 (70.9\%) of the residents were convinced that frequent posts effected their health negatively, 33 (18.1) of them were convinced that frequent posts had no negative effect on their health. As 31 (17\%) of the residents think that they can get enough rest between their posts, 107 (58.8\%) of them think they can not get enough rest between the posts. While 72 (39.5\%) of the residents consider that they are not depressed, 67 (36.8\%) of them consider themselves to have depression. As $94(51.6 \%)$ of the residents think that their performance would be higher in a regular post schedule than in an irregular post schedule; 48 (26.3\%) of them do not think that their performance would be higher in a regular post schedulethan in an irregular post schedule. While $83(45.6 \%)$ of the residents are convinced that they can use their spare time more efficiently between their posts in a regular post schedule, 47 (25.8\%) of them are convinced that they can not use their spare time between their posts more efficiently in a regular post schedule than in an irregular post schedule. As 106 (58\%) of the residents consider practicing in an EM service more advantageous compared to other services, 35 (19.2\%) of them do not consider practicing in an EM service as more advantageous compared to other services (Table 4).

No statistically significant relationship has found between the regularity and/or irregularity of the post schedules and the absence of any sleeping problems as difficulty in falling asleep, waking up frequently, or not getting enough sleep among emergency medical residents $(p=0.825)$. The absence of any sleeping problems such as difficulty in falling asleep, waking up frequently, or not getting enough sleep among emergency

Table 3. Comparison of theresidents' thoughts on fatigue, error-occupational accidents, exhaustion, relations with patients and relatives through time spent on duty

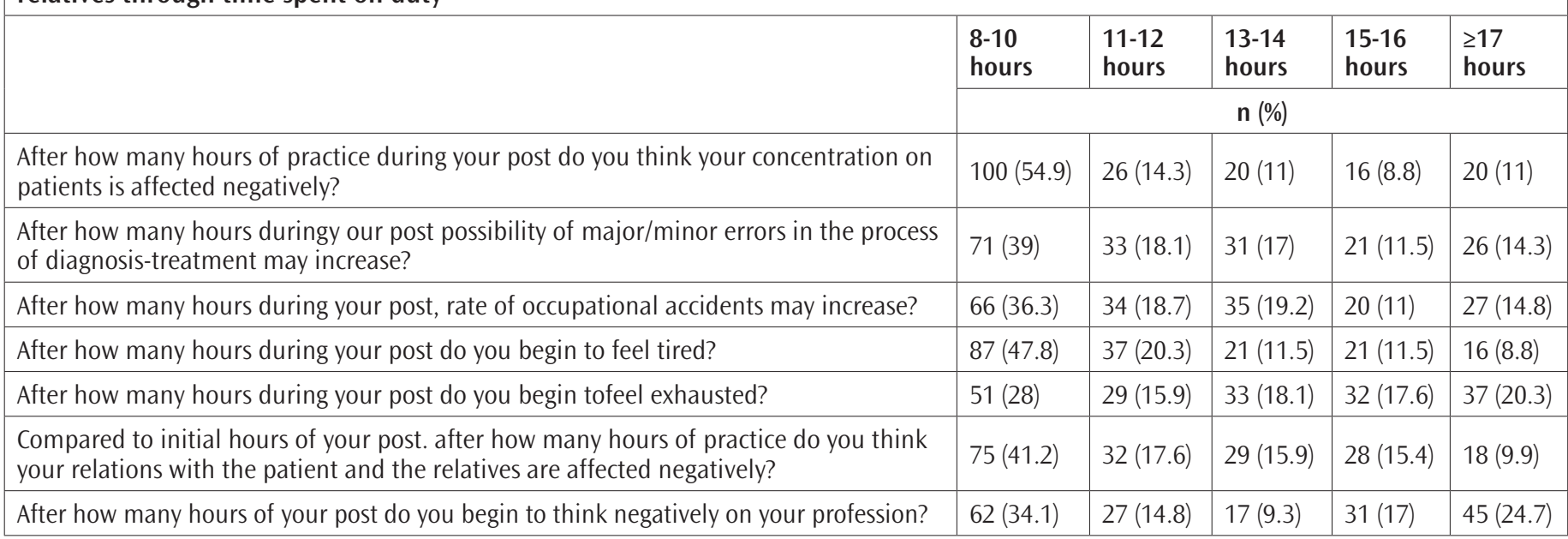




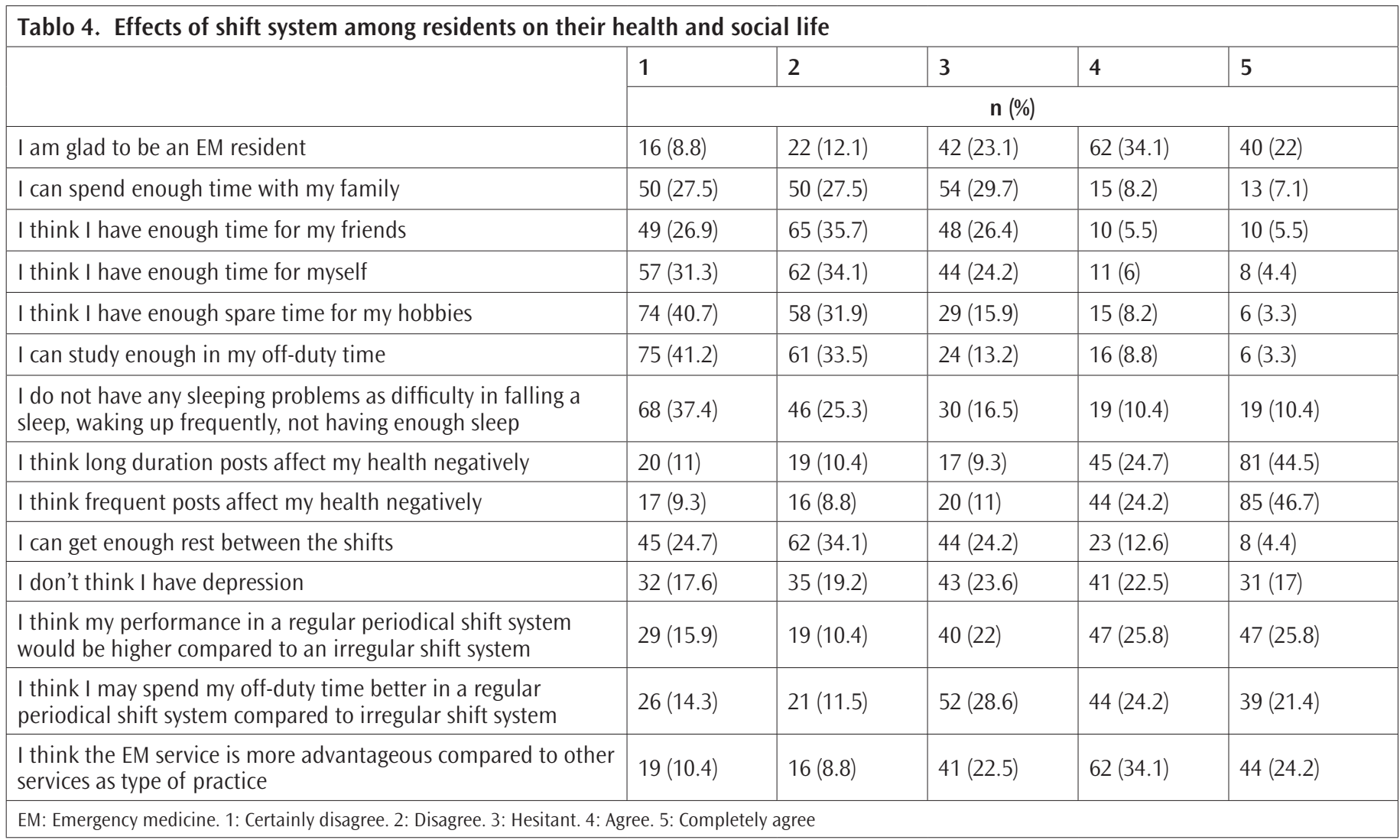

medical residents were significantly higher among the ones practicing 24-hour posts $(p=0.040$ ) (Table 5).

There was no statistically significant association found between the idea that the residents get enough rest between the posts, and the regularity/irregularity of the post schedule; however, the thought that participants get enough rest was significantly higher among the residents working 24-hour posts (Table 5).

Higher rate of residents who practice periodical posts in constant order, have reported being able to rest enough $(p<0.001)$. Also, changes in the relations with the patients and patient relatives, and a negative attitude towards the profession has been observed more among the residents practicing irregular posts $(p<0.001)$.

\section{Discussion}

EM services cause exhaustion in their staff rapidly because of the heavy work load, for this rea-son they operate with a different system compared to other medical services and ifferent systems of working order have been put to use in these 24-hour services, for attaining highest efficiency with minimal complications and minimal malpractice (6). Studies on emergency services establish that the attending physicians frequently prefer night posts, and the patients' need for the physicians during night posts increase their professional contentment (7).
It has been declared that the inconvenient conditions increase the risk of substance abuse among emergency medical service staff (8). Higher use of drugs and alcohol have been reported on shift systems (9). During our study although alcohol and cigarettes have been asked, no drug related questions have been included because of the reservation of the physiciansfor the legislation concerning civil servants. However, among the residents, the ratio of smoking as $46.7 \%$, and consumption of alcohol as $52.7 \%$, has been established in this study. It has been considered that residents are prone to substance abuse because of inconvenient hours of work, intense workload and other stress factors.

Shift patterns are associated with higher rates of comorbidity $(10,11)$. In this study rates of chronic diseases have been documented as $13.7 \%$. Considering the age range of our study, this ratio can be considered to be high. It may be stated that frequency of chronic diseases increases depending on the cumulating stress factors, chronic fatigue and irregular hours of work. Although it has been shown to increase individuals' quality of life, irregular work and shift patterns have been stated to be major stress factors $(6,8)$.

Although 12-hour shift systems are utilised commonly, it has been documented that 12-hour shift systems are exhausting, and for that reason 8-hour shift patterns are preferred due to fact that errors and occupational accidents increase in the last 
Tablo 5. Relation of shift order and type of shift with the sleeping patern. getting enough rest. change in relations with patient and relatives on different shifts and negative view on profession

\begin{tabular}{|c|c|c|c|c|c|c|}
\hline & \multicolumn{2}{|c|}{ Shift order } & \multicolumn{4}{|c|}{ Type of shift } \\
\hline & Regular & Irregular & $8 / 16$ & $12 / 12$ & 24 & Other \\
\hline \multicolumn{7}{|l|}{ Sleeping problem } \\
\hline Neutral & $2(10 \%)$ & $28(17.2 \%)$ & $17(16.3 \%)$ & $4(30.7 \%)$ & $4(8.5 \%)$ & $5(27.7 \%)$ \\
\hline None & $2(10 \%)$ & $36(22.2 \%)$ & $17(16.3 \%)$ & $3(23 \%)$ & $18(38.2 \%)$ & - \\
\hline \multicolumn{7}{|c|}{ Can get enough rest? } \\
\hline Yes & $18(47.4)$ & $15(10.2)$ & $13(50)$ & $3(11.5)$ & $7(26.9)$ & $3(11.5)$ \\
\hline Neutral & $10(26.3)$ & $10(6.8)$ & $13(56.5)$ & $2(8.7)$ & $6(26.1)$ & $2(8.7)$ \\
\hline No & $10(26.3)$ & $123(83)$ & $78(58.6)$ & $8(6)$ & $34(25.6)$ & $13(9.8)$ \\
\hline Neutral & $12(31.6)$ & $17(11.3)$ & $18(54.5)$ & $5(15.2)$ & $8(24.2)$ & $2(6.1)$ \\
\hline No & $15(39.5)$ & $11(7.3)$ & $10(52.6)$ & $2(10.5)$ & $4(21.1)$ & $3(15.8)$ \\
\hline$p$ value & \multicolumn{2}{|l|}{$<0.001$} & \multicolumn{4}{|l|}{0.782} \\
\hline \multicolumn{7}{|c|}{ Negative view on profession } \\
\hline Thinking badly & $15(6.3)$ & $112(93.7)$ & $76(59.8)$ & $9(7.1)$ & $31(24.4)$ & $11(8.7)$ \\
\hline Neutral & $5(10.3)$ & $21(89.7)$ & $14(48.3)$ & $2(6.9)$ & $9(31)$ & $4(13.8)$ \\
\hline Not thinking badly & $18(34.6)$ & $16(65.4)$ & $14(53.8)$ & $2(7.7)$ & $7(26.9)$ & $3(11.5)$ \\
\hline$p$ value & \multicolumn{2}{|l|}{0.001} & \multicolumn{4}{|l|}{0.805} \\
\hline
\end{tabular}

few hours of 12-hour shifts and shiftswhich are regular and in patterns of less than 12 hours can prevent health problems and experiencing problems in social environment $(8,12,13)$. In our study, $71.4 \%$ of the residents were convinced that posts had to be regular. While the most frequent shift pattern practiced by the residents included in this study has been 8/16 post system, shift pattern preferred the most was also 8/16 post system (31.3\%). As to the residents' content with the shift pattern they prac-tice, highest ratio of contentment belonged to the residents practicing 24-hour post systems (42.1\%). Although pysicians have preferred 8-hour shift systems in many studies, in our study physicians practicing 24-hour shift systems were content with their existing working order.

Working in shifts lead to exhaustion in physicians working in emergency services mostly due to working in shift systems and prolonged shifts, and a short nap at night can decrease the amount of exhaustion $(14,15)$. In our study it has been demonstrated that physicians are getting tired after 8 hours of duty, they start to get exhausted and begin to lose their concentration, the possibility of malpractice and occupational accidents increase, and they are prone to have negative views regarding their profession. We convinced that the possibility of malftunction and occupational accidents increases on behalf of the physicians because of their lessening amount of energy and concentration, increasing need of sleep and stress. We consider that the physician faces with instant and/or long-termoccupational problems as a result of the process and we have concerns on the matter.

Majority of the EM service staff resist sleeping idea during the day due toparticipate their familial or social life. This might cause negative attitudes during individuals' interaction with their family and social environment (8). Irregularity of the duty hours,serious loss of energy after night shifts, longer shifts, frequent posts, and weekend duties, subsequent night duties insuffi-cient control over the working hours and the flexibility of the schedule have caused the physicians to think that they can not allocate enough time for their family, social environments, maintain their life style so problems have a profound effect on the physicians' balance of work and social life, level of exhaustion, and their professional contentment, psychological and health is-sues. (16-21). In our study it was a prevalent thought that physicians could not spare enough time for themselves, their families, thieir social circles, and hobbies. No significant relation 
has been established between the post order, type of shift, number of posts, working hours, and the physicians' ability to have spare time for themselves, their families, and their social circles. No significant relations were found between the time for hobbies and the post order, num-ber of posts, and working hours. However, the conviction to have enough time for hobbies was significantly higher among physicians practicing 24-hour shifts. In our opinion working with shifts for 24 hours during the same working day by compressing the posts, creates more free days for hobbies. Thus, the time allocated to other individuals in the family and social environment may be restricted due to the fact that physicians with 24-hour posts spent this leisure time into hobbies.

Sleeping problems are common among staff practicing shifts in EM services (22). Posts shorter than 24 hours result with a higher quality of sleep, and fall asleep more easily on especially short naps during night posts not only makes it easier to tolerate the difficulties of working at night, but also makes it safer for both the physicians and the patients $(23,24)$. However, the physician has to have at least a 24-hour rest after a night post, and that, it's the only way to keep his/her circadian rhythm in order $(3,8)$. Studies on sleep deprivation have demonstrated that lack of sleep slows down the ability of the physician to perform compelling routine intellectual tasks, and also decreases the motivation of the physician (8). In accordance with published data, our study demonstrated an extensive sleeping problems among residents working with shift pattern systems; while no significant relation found between sleeping problems and order of posts, number of posts, and hours of practice, but sleeping problems were significantly less among residents having 24-hour posts. These findings interpreted as; the physicians with 24-hour posts find opportunity to sleep even if it is for short periods time; they need to come to their work-place less frequently, and they have enough time after their night posts to have their circadian rhythm recuperate itself.

There are limited data on the association between working hours and a depressive mood. It has been stated that inconvenient working conditions increase the risk of greater number of individuals needing psychiatric therapies among Emergency Service staff (8). Shift paterns are associ-ated with an increase in depression, psychological changes, divorce rates, social malfunction and psychological defects among staff maybe due to the $(25,26)$. Working in night shifts -compared to regular day work-, increases the depressive psychological mood due to the result of work load and the capacity to work (27). In our study, the thought that "physicians working in shifts fall into depression" was more prevalent. However, no significant relationship was found between this thought and the order of posts, type of shifts, number of posts, and working hours. We consider that, since the resident physicians are at the beginning of their EM practice, they have relatively less patient responsibility and they have senior physicians who may be involved in any problem they might face with the patient in the process; for that reason depressive stage has not yet begun.

A significant difference of emergency services from other branches is that most of the opera-tions conducted are observed by the patient relatives; and that leads to an extra amount of stress on the physician (3). Also, irregular and shift pattern working hours has been stated as one of the major causes of stress in literature (8). In our study, the thought that relations with the pa-tient and patient relatives display no difference among posts in regular shift patterns, whereas they display a fluctuation from post to post in irregular shift patterns, was prevalent. No significant relationship was established between shift patterns, number of posts, working hours and therelations with patients and patient relatives; however, there was a significant relationship between the order of posts and the relationship with patient and patient relatives.

The exhaustion and sleeping problems caused by the shift systems and frequent night posts, lead to weaker decision process and weaker cognitive functions, a decrease in psychomotor performance, and an increase in negative psychological states (confusion, stress and irritability) (28-30). In our study it has been observed that shift pattern post systems lead the physicians to have negative thoughts on their profession. Although no significant relationship between negative thoughts on profession and the shift pattern of the posts, number of posts and work hours has found, it has been confirmed that residents practicing in irregular shift patterns had more negative thoughts on their profession.

\section{Study Limitations}

This study depends on a national basis so the results have to be validated with international results. The sleeping problem was only asked to the participant, we did not apply a guideline, the data about sleeping problem is subjective.

\section{Conclusion}

Proper arrangement of the shift pattern systems and the number of posts which have been indispensable for emergency medicine systems not only effect the physicians' social life, but also effect thetherapeutic approach to the patients and patient relations.

\section{Ethics}

Ethics Committee Approval: This prospective study was performed with the Institutional Review Board of Ankara Numune Training and Research Hospital protocol approval date: 01/06/2016 and number: E-16-938. 
Informed Consent: Before the survey, the participants were informed about the study and those who accepted were asked to participate in the survey online.

Peer-review: Externally and internally peer-reviewed.

\section{Authorship Contributions}

Concept: I.A., B.M.S., Design: I.A., B.M.S., Data Collection or Processing: I.A., M.D.I.., S.E.Ü., Analysis or Interpretation: I.A., B.M.S., Literature Search: İ.A., M.D.İ., S.E.Ü., Writing: I.A., B.M.S., M.D.I., S.E.Ü.

Conflict of Interest: No conflict of interest was declared by the authors.

Financial Disclosure: The authors declared that this study received no financial support.

\section{References}

1. Houry D, Shockley LW, Markovchick V. Wellness issues and the emergency medicine resident. Ann Emerg Med. 2000;35:394-7.

2. Butterfield PS. The stress of residency: a review of the literature. Arch Int Med. 1988; 148:1428-35.

3. Cevik AA, Holliman CJ, Yanturali S. Emergency physicians and "burn out" syndrome. Ulus Travma Acil Cerrahi Derg. 2003;9:85-9.

4. McNamara RM. Physician Wellness. Web site. Available at: http://www. emedicine.medscape.com/emerg/topic678.html (Accessed December 12, 2016).

5. Krakow B, Hauswald M, Tandberg D, Sklar D. Floating nights: a 5-year experience with an innovative ED schedule. Am J Emerg Med. 1994;12:51720.

6. Takakuwa KM, Biros MH, Ruddy RM, Fitz Gerald M, Shofer FS. A national survey of academic emergency medicine leaders on the physician workforce and institutional workforce and aging policies. Acad Med. 2013;88:269-75.

7. Steele MT, McNamara RM, Smith-Coggins R, Watson WA. Morningnesseveningness preferences of emergency medicine residents are skewed toward eveningness. Acad Emerg Med. 1997;4:699-705.

8. Whitehead DC, Thomas H, Slapper DR. A rational approach to shift work in emergency medicine. Ann Emerg Med. 1992;21:1250-8.

9. Gordon NP, Cleary PD, Parker CE, Czeisler CA. The prevalence and health impact of shiftwork. Am J Public Health. 1986;76:1225-8.

10. Chau NP, Mallion JM, de Gaudemaris R, Ruche E, Siche JP, Pelen O, et al. Twenty-four-hour ambulatory blood pressure in shift workers. Circulation. 1989;80:341-7.

11. Binder LS, Allison EJ, Prosser R, Robinson W, Spaite D, Hamilton GC. 24-hour coverage in academic emergency medicine: ways of dealing with the issue. Ann Emerg Med. 1990;19:430-4.

12. Steele MT, Watson WA. Emergency medicine residency faculty scheduling: current practice and recent changes. Ann Emerg Med. 1995;25:321-4.

13. Steele MT, Ma OJ, Watson WA, Thomas HA Jr. Emergency medicine residents' shiftwork tolerance and preference. Acad Emerg Med. 2000;7:670-3.
14. Tucker P, Bejerot E, Kecklund G, Aronsson G, Åkerstedt T. Doctors' work hours in Sweden: their impact on sleep, health, work-family balance, patient care and thoughts about work. Available at: https://www. stressforskning.su.se/polopoly_fs/1.127787.1363088730!/menu/standard/ file/Forskningsaktuellt_2.pdf (Accessed December 17, 2018).

15. Nijp HH, Beckers DG, Geurts SA, Tucker P, Kompier MA. Systematic review on the association between employee worktime control and work-non-work balance, health and well-being, and job-related outcomes. Scand J Work Environ Health. 2012:299-313.

16. Blachowicz E, Letizia M. The challenges of shift work. Med Surg Nursing. 2006;15:274-80.

17. Tucker P, Bejerot E, Kecklund G, Aronsson G, Åkerstedt T. The impact of work time control on physicians' sleep and well-being. Appl Ergon. 2015;47:10916.

18. Brown M, Tucker P, Rapport F, Hutchings H, Dahlgren A, Davies G, et al. The impact of shift patterns on junior doctors' perceptions of fatigue, training, work/life balance and the role of social support. Qual Saf Health Care. 2010;19:e36

19. Heponiemi T, Kouvonen A, Vänskä J, Halila H, Sinervo T, Kivimäki M, et al. Effects of active on-call hours on physicians' turnover intentions and wellbeing. Scand J Work Environ Health. 2008:356-63.

20. Smith A, Morris P, Rowell K, Clarke S, Jones T, Channer K. Junior doctors and the full shift rota-psychological and hormonal changes: a comparative crosssectional study. Clin Med. 2006;6:174-7.

21. Clem KJ, Promes SB, Glickman SW, Shah A, Finkel MA, Pietrobon R, et al Factors enhancing career satisfaction among female emergency physicians. Ann Emerg Med. 2008;51:723-8.e8.

22. Sack R, Auckley D, Auger R, Carskadon M, Wright K, Vitiello M, et al. Circadian rhythm sleep disorders: Part I, basic prin-ciples, shift work and jet lag disorders. Sleep. 2007;30:1460-83.

23. Landrigan CP, Rothschild JM, Cronin JW, Kaushal R, Burdick E, Katz JT, et al Effect of reducing interns' work hours on serious medical errors in intensive care units. N Eng J Med. 2004;351:1838-48.

24. Lockley SW, Cronin JW, Evans EE, Cade BE, Lee C], Landrigan CP, et al. Effect of reducing interns' weekly work hours on sleep and attentional failures. N Eng J Med. 2004;351:1829-37.

25. Frese M, Okonek K. Reasons to leave shiftwork and psychological and psychosomatic complaints of former shiftworkers. J Appl Psychol. 1984;69:509-14.

26. Florida-James $\mathrm{G}$, Wallymahmed A, Reilly T. Effects of nocturnal shiftwork on mood states of student nurses. Chronobiol Int. 1996;13:59-69.

27. Driesen K, Jansen NW, Kant I, Mohren DC, van Amelsvoort LG. Depressed mood in the working population: associations with work schedules and working hours. Chronobiol Int. 2010;27:1062-79.

28. Cheng YH, Roach GD, Petrilli R. Current and future directions in clinical fatigue management: An update for emergency medicine practitioners. Emerg Med Australas. 2014;26:640-4

29. Lamond N, Dorrian J, Roach G, McCulloch K, Holmes A, Burgess H, et al. The impact of a week of simulated night work on sleep, circadian phase, and performance. Occup Environ Med. 2003;60:e13.

30. Bonnet MH, Arand DL. Clinical effects of sleep fragmentation versus sleep deprivation. Sleep Med Rev. 2003;7:297-310. 